\title{
Onychomadesis outbreak linked to hand, foot, and mouth disease, Spain, July 2008
}

J Guimbao¹, P Rodrigo (mrodrigo@aragon.es) ${ }^{1}$, M J Albertoํ, M Omeñaca ${ }^{2}$

1. Epidemiological Surveillance Unit, Saragossa, Spain

2. Miguel Servet Hospital, Microbiological Laboratory, Saragossa, Spain

Guimbao J, Rodrigo P, Alberto MJ, Omeñaca M. Onychomadesis outbreak linked to hand, foot, and mouth disease, Spain, July 2008 . Euro Surveill. 2010;15(37): pii=19663. Available online: http://www.eurosurveillance.org/ViewArticle.aspx?Articleld=19663

In July 2008 an onychomadesis outbreak in a nursery setting was reported in Saragossa (Spain). Some of the cases had previously suffered from hand, foot and mouth disease (HFMD). In order to study the outbreak and to determine the relation between the two diseases, two epidemiological studies were conducted: a descriptive study focused on cases and a retrospective cohort study. Samples from stool, pharynx and nails were obtained from cases for microbiological analysis. During the study period, 27 children fulfilled the case definition. The average age was 1.8 years. A case shed on average four nails (minimum one maximum twelve). Twenty-four of the 27 cases had previously presented with HFMD which started an average of 40 days before the onset of onychomadesis (relative risk: 14). Unidentified non-polio enterovirus $(n=10)$, coxsackie $B_{1}(n=4)$ and coxsackie $B 2$ virus $(n=3)$ were isolated in 28 specimens obtained from 14 cases. The analysis showed a strong association between HMFD and onychomadesis. Microbiological results have not been conclusive; consequently more studies are necessary to determine the causal agent of infectious onychomadesis.

\section{Introduction}

Onychomadesis is an acute, painless, non-inflammatory disease that affects the nail matrix $[1,2]$. Patients present a wide clinical profile from transverse ridging of the nail plate (Beau's lines) up to complete nail shedding. Apart from serious generalised diseases, trauma or exposure to specific drugs, most cases have been considered idiopathic. Isolated onychomadesis cases following hand, foot and mouth disease (HFMD) have been described in the United States [1] and in France [3]. More recently, HFMD-related onychomadesis cases have been observed in Spain - Valencia [4] and Valladolid [8] - and also in Finland [10]. HFMD is a disease caused by enteroviruses (genus Enterovirus, family Picornaviridae). Complications from HFMD are rare, but pneumonia, meningitis or encephalitis may occur. HFMD is characterised by a low grade fever, a vesicular eruption of the hands, feet and ulcerations on the tongue, soft palate, buccal mucosa or gums. These symptoms usually resolve spontaneously after six days. It is assumed that virus replication damages the nail matrix and results in temporary nail dystrophy [3].

In July 2008 , a paediatrician reported an onychomadesis outbreak to the Epidemiological Surveillance Unit of Saragossa, Spain. The cases were children who attended two nurseries in Ricla and Calatorao, two adjacent villages situated in Aragon (north-east Spain). Some cases had suffered from HFMD a few weeks before. A descriptive study was carried out, and a retrospective cohort study was performed aiming to investigate the relation between onychomadesis and HFMD.

\section{Methods \\ Study design}

Two studies were performed. A descriptive study focused on cases to describe the basic person-placetime variables of the outbreak, and a retrospective cohort study to assess the onychomadesis risk after HFMD. The cohort members were the children who attended the two nurseries during follow-up period from 1 May 2008 (two month before disease onset of the first case of onychomadesis) to 15 July 2008 (a week after disease onset of the last case). The followup period was chosen to correspond to the average time by which HFMD precedes onychomadesis $[4,8,10]$.

\section{Data source}

The nurseries' records provided the target population. An ad hoc epidemiological questionnaire was designed collecting the following variables:

- General information: sex, date of birth, previous illness or underlying condition (yes/no/which one), nursery attended.

- During the follow-up period: lunches in the nursery, HFMD diagnosis (yes/no), symptoms (type, onset date, duration), onychomadesis diagnosis (yes/no, onset date, number of nails shed or injured), contact to other cases, medication, nail trauma. In the questionnaire, travel history with date and place of travel was collected, mainly to areas with recent HFMD outbreaks. 
- Following onychomadesis symptoms: isolation at home, complications (admission to hospital).

The data were obtained from the children's families through telephone interview. Informed consent was requested from the families. Medical information was validated in paediatric records from the local medical office.

\section{Case definitions}

A case of onychomadesis was defined as a cohort member who during the follow-up period presented changes on the nail plates followed by complete nail shedding [1,2]. An HFMD case was defined as a cohort member who, at least for three days, presented a macular-vesicular rash involving oropharynx area and limbs and/or buttocks (classical herpangina) $[1,5,6]$.

\section{Microbiological analysis}

Stool, pharynx exudates and nail specimens were obtained from onychomadesis cases. The specimens were sent to the microbiological reference laboratory at the Miguel Servet Hospital in Saragossa to be analysed for viruses. Enteroviruses were isolated on MRC-5 human embryonic lung fibroblasts or a human rhabdomyosarcoma (RD) cell line, and the presence of non-polio enteroviruses was confirmed using indirect inmunofluorescence [9]. The isolates were serotyped at the National Microbiological Centre in Majadahonda by PCR of the 5'-non-coding region. If this PCR was positive, a specific region of the $\mathrm{VP}_{1}$ capsid protein gene was amplified and sequenced [9]. If the first PCR was negative, the isolate was considered as an unidentified non-polio enterovirus.

\section{Statistical analysis}

Student's t-test and the ANOVA test were applied to compare quantitative variables, and the chi-square test was used for qualitative variables; $p$-values less than 0.05 were considered statistically significant.

The risk of developing onychomadesis and attack rates were calculated for the different variables or

\section{FIGURE}

Epidemic curve, onychomadesis outbreak, Saragossa, Spain, July $2008(\mathrm{n}=27)$

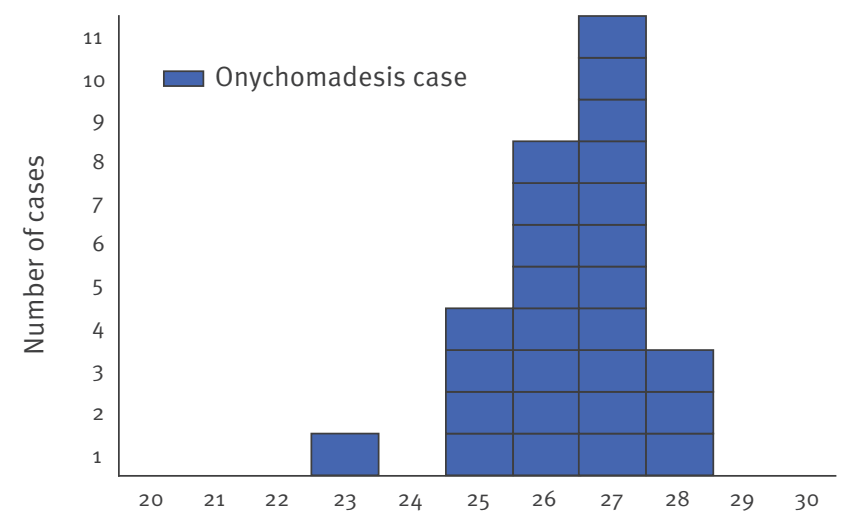

risk factors. The relative risk (RR) was calculated as the ratio of the two attack rates (with versus without prior risk factor such as HFMD); confidence intervals (CI) at 95\% were estimated. A stratified analysis was performed to detect a possible age-HFMD interaction, and the risk of onychomadesis was estimated for the children with prior HFMD and those without in each age group.

\section{Results}

\section{Descriptive study}

Ricla nursery had 54 children and a staff of four child carers and one cleaner. The staff of Calatorao nursery comprised three child carers for 48 children. The nurseries did not have meal service, but some children ate food they had brought from home. Interview responses were not available for 14 of the 102 children, leaving a total study population of 88 children.

None of the staff members developed onychomadesis or HFMD during the follow-up period. However, 27 children showed clinical symptoms that fulfilled the case definition for onychomadesis, 15 children in Ricla (attack rate: $35 \%$ ) and 12 children in Calatorao (attack rate: $26 \%$ ). Of those 27,14 were girls, and the age average was 21 months (standard deviation 6 months), ranging from 11 to 40 months. The average number of shed nails per case was four, with a minimum of one and a maximum of twelve. Three children had an underlying condition: coeliac disease, bronchitis (undergoing cortisone treatment) and hereditary spherocytosis (undergoing folic acid treatment)..

The date of onset of the first case was on 7 June 2008 (23rd epidemiological week) and of the last case on 7 July 2008 (28th epidemiological week). The epidemic curve reaches a peak of 11 cases in the 27th epidemiological week (Figure).

Of the 88 children who participated in the study, 32 had a record of HFMD, and 24 of them developed onychomadesis. HFMD in those 24 cases had started an average of 40 days before onset of onychomadesis and the changes on the nail plates, followed by complete nail shedding, appeared after an asymptomatic period. Spontaneous resolution of HFMD symptoms occurred on average within eight days.

\section{Retrospective cohort study}

The analysis (Table 1) showed a significant association between onychomadesis and prior HFMD (RR: 14; $95 \% \mathrm{Cl}: 4 \cdot 57-42.86)$. The onychomadesis attack rate changed with age: It was $55 \%$ in the youngest group (under two years-old (9-23 months)), 30\% in the middle group (2-3-years-old (24-32 months)) and 4\% in the oldest group (3-3.5-years-old (33-42 months)). The association between onychomadesis and prior HFMD remained when analysed separately for each age group (Table 2). 
No significant associations were found between onychomadesis and the rest of the studied variables during the follow-up period: sex, nursery location, lunches in the nursery, travel history and underlying condition. Previous trauma and regular medication were considered but were not reported among the children in this study and could therefore not be evaluated as a risk factor onychomadesis.

\section{Microbiological results}

We obtained 28 specimens from 14 onychomadesis cases for microbiological analysis. The time between nail shedding and sample collection was between one and three weeks. The first cases had symptom onset in week 23. Enterovirus was isolated from 17 specimens $(61 \%)$ collected from 11 of the 14 cases. These isolates were identified as: coxsakievirus B2 (two cases, both with previous HFMD), coxsakievirus B1 (two cases, both with previous HFMD) and non-polio enterovirus (seven cases, one with previous HFMD). Table 3 shows aggregated data by case and specimen type.

\section{TABLE 1}

Risk factors for onychomadesis, outbreak in Saragossa, Spain, July 2008 (n=88 study participants)

\begin{tabular}{|c|c|c|c|c|c|}
\hline Risk factors & Study participants & Cases & Attack rate (\%) & Relative risk & $\begin{array}{l}95 \% \text { confidence } \\
\text { interval }\end{array}$ \\
\hline \multicolumn{6}{|l|}{ Nursery location } \\
\hline Ricla & 43 & 15 & $34 \cdot 9$ & \multirow{2}{*}{1.3} & \multirow{2}{*}{$0.69-2.46$} \\
\hline Calatorao & 45 & 12 & 26.7 & & \\
\hline \multicolumn{6}{|l|}{ Sex } \\
\hline Female & 44 & 14 & 31.8 & \multirow{2}{*}{1.1} & \multirow{2}{*}{$0.57-2.01$} \\
\hline Male & 44 & 13 & 29.5 & & \\
\hline \multicolumn{6}{|l|}{ Lunch in the nursery } \\
\hline Yes & 61 & 20 & 32.8 & \multirow{2}{*}{1.2} & \multirow{2}{*}{$0.56-2.41$} \\
\hline No & 25 & 7 & 28.0 & & \\
\hline Unknown & 2 & 0 & & & \\
\hline \multicolumn{6}{|l|}{ Recent travel } \\
\hline Yes & 19 & 6 & 31.6 & \multirow{2}{*}{0.66} & \multirow{2}{*}{$0.31-1.38$} \\
\hline No & 42 & 20 & 47.6 & & \\
\hline Unknown & 27 & 1 & & & \\
\hline \multicolumn{6}{|l|}{ Underlying condition } \\
\hline Yes & 3 & $1^{\mathrm{a}}$ & 33.3 & \multirow{2}{*}{0.86} & \multirow{2}{*}{$0.16-4 \cdot 42$} \\
\hline No & 65 & 25 & 38.5 & & \\
\hline Unknown & 20 & 1 & & & \\
\hline \multicolumn{6}{|l|}{ Age (years) } \\
\hline$<2$ & 33 & 18 & $54 \cdot 5$ & $16,25^{*}$ & $2.31-114.01$ \\
\hline $2-3$ & 27 & 8 & 29.6 & $7,72^{\star}$ & $1.03-57.81$ \\
\hline >3 (reference group) & 28 & 1 & 3.6 & 1 & \\
\hline \multicolumn{6}{|c|}{ Hand, foot and mouth disease } \\
\hline Yes & 32 & 24 & 75.0 & \multirow{2}{*}{$14,0^{*}$} & \multirow{2}{*}{$4 \cdot 57-42.86$} \\
\hline No & 56 & 3 & 5.4 & & \\
\hline
\end{tabular}

a Hereditary spherocytosis.

* Statistically significant at $p<0.05$

TABLE 2

Hand, foot and mouth disease record and onychomadesis by age group, Saragossa, Spain, July 2008 (n=88 study participants)

\begin{tabular}{|c|c|c|c|c|c|c|c|c|c|c|c|c|c|}
\hline \multirow{3}{*}{ Age group } & & \multicolumn{4}{|c|}{ <2 years } & \multicolumn{4}{|c|}{ 2-3 years } & \multicolumn{4}{|c|}{13 years } \\
\hline & & \multicolumn{2}{|c|}{ Onychomadesis } & \multirow[b]{2}{*}{$\mathrm{RR}$} & \multirow[b]{2}{*}{$\mathrm{Cl} 95 \%$} & \multicolumn{2}{|c|}{ Onychomadesis } & \multirow[b]{2}{*}{$\mathrm{RR}$} & \multirow[b]{2}{*}{$\mathrm{Cl} 95 \%$} & \multicolumn{2}{|c|}{ Onychomadesis } & \multirow[b]{2}{*}{$\mathrm{RR}^{\mathrm{a}}$} & \multirow[b]{2}{*}{$\mathrm{Cl} 95 \%$} \\
\hline & & Yes & No & & & Yes & No & & & Yes & No & & \\
\hline \multirow{2}{*}{ HFMD } & Yes & 16 & 2 & \multirow{2}{*}{6.66} & \multirow{2}{*}{$1.8-24.4^{*}$} & 7 & 4 & \multirow{2}{*}{10.18} & \multirow{2}{*}{$1.4-71.5^{*}$} & 1 & 2 & \multirow{2}{*}{8.66} & \multirow{2}{*}{$0,7-105.6$} \\
\hline & No & 2 & 13 & & & 1 & 15 & & & 0 & 25 & & \\
\hline Total & & 18 & 15 & & & 8 & 19 & & & 1 & 27 & & \\
\hline
\end{tabular}

$\mathrm{Cl}$ : confidence interval; HFMD: hand, foot and mouth disease; RR: relative risk.

a RR was calculated with 1 case in the box without cases.

* Chi-square p<0.05. 


\section{Discussion}

This study describes an onychomadesis outbreak in children. Our analysis showed a strong association between onychomadesis and previous HFMD (RR: 14). HFMD happened 40 days before onychomadesis. That association has already been pointed out by Clementz and Mancini [1], Bernier et al. [3], Redondo et al. [8] and Österback et al. [10]. There are few outbreaks in which it has been possible to isolate viruses from onychomadesis cases. In an HFMD outbreak in Finland in 2008, shed nails were obtained from two siblings who had HFMD eight weeks before the nail shedding; the virus in one of them was identified as coxsackievirus A6 [10].

Our estimations also confirm the results of Salazar et al. [2] who analysed a community outbreak of onychomadesis in Valencia (Spain) in 2008. These authors found that 121 cases $(59,6 \%)$ had a record of previous HFMD, compared with only $13,6 \%$ of controls (odds ratio: 14.9$)$. They further found that HFMD had occurred an average of 39 days before onychomadesis, similar to the outbreak in Valladolid (Spain) [8] with an average of 42 days, and the one in Finland in 2008 [10], where the children shed fingernails and/or toenails within one to two months after HFMD.

In addition, we found a significant association between age and onychomadesis, but age was not a confounder because the stratified analysis showed that there was an association between onychomadesis and previous HFMD in each age group.

Taken together, we think that onychomadesis could be a late complication of HFMD, mainly in young children. Two limitations could be considered. Firstly, 14 children did not participate in the study, but we do not think this had a relevant effect on the results since the non-responders did not visit the medical office during the study period and it is therefore not likely that they fell ill. Secondly, recall bias is described in studies based on interviews, but in our case the answers were validated in the paediatric records from the local medical office.

HFMD epidemics have primarily been associated with different enteroviruses, such as CVA16, echovirus 4 [7] or enterovirus 71. Those caused by enterovirus 71 have occurred more frequently in Southeast Asia in recent years. An outbreak in Singapore, described by Chan et al. [6] had thousands of cases, but onychomadesis was not reported as a complication of HFMD in that epidemic. Other enteroviruses, such as CVA6 and CVA10, and new genetic variants of these viruses, were a primary pathogens associated with HFMD during a nationwide outbreak in Finland in autumn 2008 in which onychmadesis cases following HFMD were observed $[10,11]$.

In an outbreak of enterovirus in a nursery it is important to introduce control measures such as staff hand washing, disinfection of all materials exposed to potentially infected biological fluids, increased staff hygiene precautions in the kitchen, and use of a different basin for bathing each baby [12].

In our study, the microbiological results were not conclusive. Moreover, at least two different viruses were isolated from the onychomadesis cases: coxsackie virus $B_{1}$, coxsackie virus $B_{2}$ and unidentified non-poliovirus enterovirus, suggesting that co-circulation of coxsackie virus $B_{1}$ and $B_{2}$ was likely. These two viruses are not usually associated with HFMD. The number of

TABLE 3

Microbiological results, onychomadesis outbreak, Saragossa, Spain, July 2008 (n=14 cases)

\begin{tabular}{|c|c|c|c|c|}
\hline $\begin{array}{l}\text { Case } \\
\text { number }\end{array}$ & $\begin{array}{l}\text { Total samples } \\
\text { for case }\end{array}$ & Stool & Pharynx smear & Nail \\
\hline 1 & 2 & Coxsackievirus B2 & Negative & ND \\
\hline 2 & 3 & Coxsackievirus B2 (2 samples) & Negative & ND \\
\hline 3 & 2 & Unidentified non-polio enterovirus & Unidentified non-polio enterovirus & ND \\
\hline 4 & 2 & Negative & Unidentified non-polio enterovirus & ND \\
\hline 5 & 1 & ND & Unidentified non-polio enterovirus & ND \\
\hline 6 & 2 & ND & Negative & $\begin{array}{l}\text { Unidentified } \\
\text { non-polio enterovirus }\end{array}$ \\
\hline 7 & 2 & Unidentified non-polio enterovirus & Unidentified non-polio enterovirus & ND \\
\hline 8 & 2 & Negative & Unidentified non-polio enterovirus & ND \\
\hline 9 & 1 & ND & Unidentified non-polio enterovirus & ND \\
\hline 10 & 3 & Coxsackievirus B1 (2 samples) & Unidentified non-polio enterovirus & ND \\
\hline 11 & 3 & Coxsackievirus B1 (2 samples) & Negative & ND \\
\hline 12 & 2 & Negative & Negative & ND \\
\hline 13 & 2 & Negative & Negative & ND \\
\hline 14 & 1 & ND & Negative & ND \\
\hline Total & 28 & 13 & 14 & 1 \\
\hline
\end{tabular}

ND: not done. 
enterovirus-positive specimens could have been higher if the samples had been collected in the acute phase or from subclinical cases that were sustaining the outbreak, but our number of $61 \%$ is similar to the proportion of positive specimens in other outbreaks such as the $66 \%$ observed in Finland [10].

In conclusion, more studies are needed to settle doubts about the aetiology of possibly infectious onychomadesis.

\section{Acknowledgements}

We thank Annick Lenglet, Alberto Vergara, Juan Pablo Alonso, Begoña Adiego for the revision of the article. We thank Carmen Bueno for her contribution to following up on the children.

\section{References}

1. Clementz GC, Mancini AJ. Nail matrix arrest following hand foot-mouth disease: a report of five children. Pediatr Dermatol. 2000;17(1):7-11.

2. Salazar A, Borrás MJ, Cordoba J, Febrer I, Gobernado M, Guiral $S$, et al. Brote de onicomadesis asociado a Síndrome de BocaMano-Pie. [Onychomadesis outbreak associated with hand, foot and mouth disease]. Boletín Epidemiológico Semanal, 2008;16;61-4. Available from: http://www.isciii.es/htdocs/ centros/epidemiologia/boletin_semanal/beso811.pdf

3. Bernier V, Labrèze C, Bury F, Taïeb A. Nail matrix arrest in the course of hand, foot and mouth disease. Eur J Pediatr. 2001;160(11):649-51.

4. Salazar A, Febrer I, Guiral S, Gobernado M, Pujol C, Roig J. Onychomadesis outbreak in Valencia, Spain, June 2008. Euro Surveill. 2008;13(27):pii=18917. Available from: http://www. eurosurveillance.org/ViewArticle.aspx?Articleld=18917

5. Chan YF, AbuBakar S. Recombinant human enterovirus 71 in hand, foot and mouth disease patients. Emerg Infect Dis. 2004;10(8):1468-70.

6. Chan KP, Goh KT, Chong CY, Teo ES, Lau G, Ling AE. Epidemic hand, foot and mouth disease caused by human enterovirus 71, Singapore. Emerg Infect Dis. 2003;9(1):78-85.

7. Russo DH, Luchs A, Machado BC, Carmona R de C, Timenetsky $M$ do $C$. Echovirus 4 associated to hand, foot and mouth disease. Rev Inst Med Trop Sao Paulo. 2006;48(4):197-9.

8. Redondo Granado MJ. Torres Hinojal MC. Izquierdo López B. [Post viral onychomadesis outbreak in Valladolid]. [Spanish]. An Pediatr (Barc). 2009;71(5):436-9.

9. Nix WA, Oberste MS, Pallansch MA. Sensitive, seminested PCR amplification of VP1 sequences for direct identification of all enterovirus serotypes from original clinical specimens. J Clin Microbiol. 2006;44(8):2698-704

10. Österback R, Vuorinen T, Linna M, Susi P, Hyypiä, Waris M. Coxsackievirus A6 and hand, foot, and mouth disease, Finland. Emerg Infect Dis. 2009;15(9):1485-8.

11. Blomqvist S, Klemola P, Kaijalainen S, Paananen A, Simonen $M L$, Vuorinen T, et al. Co-circulation of coxsackieviruses A6 and $\mathrm{A} 10$ in hand, foot and mouth disease outbreak in Finland. J Clin Virol. 2010;48(1):49-54.

12. Huang FL, Chen $\mathrm{CH}$, Huang SK, Chen PY. An outbreak of enterovirus 71 in a nursery. Scand I Infect Dis. 2010;42(8):609-12. 